\title{
EDUCAÇÃO ESTÉTICA: [ENTRE] PAISAGENS ARTÍSTICAS E PEDAGÓGICAS
} AESTHETIC EDUCATION: [BETWEEN] ARTISTIC AND
PEDAGOGICAL LANDSCAPES EDUCACIÓN ESTÉTICA: [ENTRE] PAISAJES ARTÍSTICOS Y PEDAGÓGICOS

Elaine Schmidlin ${ }^{1}$ Jociele Lampert ${ }^{2}$ 


\section{Resumo}

$\mathrm{O}$ artigo apresenta paisagens artísticas e pedagógicas que refletem sobre educação estética, desdobradas em experiências e movimentos cartográficos presentes nos trabalhos do Grupo de Pesquisa [Entre] Paisagens, CNPq/ UDESC. Este se constitui de duas Linhas de Pesquisa, sendo que a primeira investiga o processo de criação em Arte, e a segunda o processo de criação em Arte e Educação, propondo reconfigurar outras paisagens nas formações de artes visuais, tanto em licenciatura quanto em bacharelado. A finalidade do grupo é promover articulações entre formação docente e formação poética de modo a evidenciar seu aspecto relacional. Assim, o artigo apresenta algumas dessas paisagens desenhadas pelos projetos ancorados no GP, em que cada pesquisador investiga diferentes concepções e eixos teóricos que se entrecruzam com a filosofia.

Palavras-chave: Artes Visuais; Educação Estética; Filosofia; Paisagens.

\section{Abstract}

The article presents artistic and pedagogical landscapes that reflect on aesthetic education, unfolded in experiences and cartographic movements present in the works of the Research Group [Between] Landscapes, CNPq / UDESC. This is constituted of two Lines of Research, the first investigating the process of creation in Art, and the second the process of creation in Art and Education, proposing to reconfigure other landscapes in visual arts formations, both undergraduate and baccalaureate. The purpose of the group is to promote articulations between teacher education and poetic formation in order to highlight their relational aspect. Thus, the article presents some of these landscapes designed by the projects anchored in the GP, in which each researcher investigates different conceptions and theoretical axes that intersect with philosophy.

Key-words: Visual Arts; Aesthetic education; Philosophy; Sights.
1. Professora no Programa de Pós-graduação e no curso de Licenciatura em Artes Visuais do Centro de Artes (CEART) da Universidade do Estado de Santa Catarina (UDESC). Possui Pós-doutorado pelo Instituto de Filosofia da Universidade Nova de Lisboa; Doutorado em Educação pela Universidade Federal de Santa Catarina (UFSC); Mestrado em Educação pela Universidade Federal do Paraná (UFPR) e Graduação pela Escola de Belas Artes da Universidade Federal do Rio de Janeiro (UFRJ). Integrante do Grupo de Pesquisa Entre Paisagens UDESC/CNPq. s.elaine@gmail.com

Lattes: http://lattes.cnpq.br/9781556928615419.

Orcid: https://orcid.org/0000-0002-7478-1781.
2. Desenvolveu pesquisa como professora visitante no Teachers College na Columbia University na cidade de New York como Bolsista Fulbright (2013) onde realizou estudo intitulado: ARTIST'S DIARY AND PROFESSOR'S DIARY: ROAMINGS ABOUT PAINTING EDUCATION. Doutora em Artes Visuais pela ECA/USP (2009); Mestre em Educação pela UFSM (2005). Possui Graduação em Desenho e Plástica Bacharelado em Pintura, pela Universidade Federal de Santa Maria (2002) e Licenciatura também pela Universidade Federal de Santa Maria (2003). Professora Associada na Universidade do Estado de Santa Catarina. Atua no Mestrado e Doutorado em Artes Visuais PPGAV/UDESC, como orientadora na Linha de Pesquisa de Ensino das Artes Visuais e na Graduacão em Artes Visuais DAV/UDESC. É membro do Grupo de Estudos e Pesquisa em Arte, Educação e Cultura UFSM/CNPq. Membro/ Líder do Grupo de Pesquisa Entre Paisagens UDESC/CNPq. Coordenadora do Grupo de Estudos Estúdio de Pintura Apotheke (UDESC). É Editora Chefe do Periódico Revista Apotheke. Site: www.jocielelampert.com.br e www.apothekeestudiodepintura.com - jocielelampert@uol.com.br

Lattes: http://lattes.cnpq.br/7149902931231225

Orcid: https://orcid.org/0000-0003-0963-0925 


\section{Resumen}

El artículo presenta paisajes artísticos y educativos que se reflejan en la educación estética, desplegados en los experimentos y los movimientos cartográficas presentes en el trabajo del Grupo de Investigación [Enter] paisajes, CNPq / UDESC. Está constituido por dos líneas de investigación, la primera que investiga el proceso de creación en Arte y la segunda el proceso de creación en Arte y Educación, que propone reconfigurar otros paisajes en formaciones de artes visuales, tanto de pregrado como de bachillerato. El propósito del grupo es promover vínculos entre la formación del profesorado y la formación poética con el fin de resaltar su aspecto relacional. Por lo tanto, el artículo presenta algunos de estos paisajes dibujados por los proyectos anclados en GP, donde cada investigador investiga diferentes concepciones teóricas y ejes que se cruzan con la filosofía.

Palabras-clave: Artes visuales; Educación estética; Filosofía; Paisajes.

ISSN: 2175-2346 


\section{INTRODUÇÃO}

Inicialmente, o texto caracteriza o significado do termo paisagem compreendido pelo Grupo de Pesquisa (GP) para, na sequência, explicar as diferentes concepções teóricas que se entrecruzam com a filosofia da diferença em Gilles Deleuze e com a filosofia pragmática de John Dewey. Os itens paisagem I e II, respectivamente, trazem esses aportes teóricos e as pesquisas articuladas a eles, em torno das formações, artística e docente. Finalmente, conclui-se em uma interlocução conceitual com a poética e a educação estética e, espera-se, com este artigo, apresentar os atravessamentos sensíveis e conceituais que nos fazem agir, experimentar ou pensar acerca das áreas, artes visuais e educação. Assim, o GP, enquanto um movimento poético e pedagógico, propõe pensar o lugar da pesquisa como acontecimento e experiência.

\section{PAISAGEM}

Anne Cauquelin (2007), ao comentar sobre a noção conceitual de paisagem argumenta que a mesma seria apenas um artifício de uma constituição ilusória criada por construções historicamente culturais e intelectuais ao longo do tempo, compostas por milhares de dobras e memórias, que se multiplicam em variações infinitas. Desse modo, entre essas variações, a paisagem não pode ser submetida apenas a uma percepção da natureza, uma vez que é possível construir outras imagens e, consequentemente, outras teorias do estatuto da paisagem ao longo da história.

Por outro lado, o termo paisagem vem sendo utilizado com mais frequência na contemporaneidade em áreas do conhecimento como a geografia, a biologia, o urbanismo e a política. Na história da arte, o termo é usado para explicar um gênero de pintura. Entretanto, para Maderuelo (2010), a paisagem não é uma realidade física, ou objetos, ou a própria natureza em si, mas sim uma construção, uma elaboração mental que ativamos por meio de fenômenos culturais. Desta forma, mapas e telas podem, também, configurar percursos tecidos a partir de experiências.

Portanto, para o Grupo de Pesquisa, a noção conceitual de paisagem desfaz a evidência da história da edificação da paisagem unicamente como representação da natureza, mas configura-se como o lugar de experiências e processos, em que a paisagem não tem nenhuma característica representacional com a natureza, mas possibilita apresentar um cenário para a apresentação de duas noções fundamentais para o GP. Uma delas, apresentada na paisagem I, é a noção de acontecimento, esse efeito incorporal na superfície, segundo Gilles Deleuze, que se ancora na filosofia da diferença. Para ele, "o acontecimento não é o que acontece (acidente), ele é no que acontece o puro expresso que nos dá sinal e nos espera" (2003, p. 152). Desse modo, as pesquisas atreladas a essa concepção teórica estão apoiadas no cruzamento entre questões pedagógicas e poéticas, realçando o acontecimento que o perpassa. Nesse caso, o que interessa é ativar o que se passa entre duas áreas territoriais denominadas arte e educação e ressaltar os devires que ocorrem entre elas. Nesse movimento de desterritorialização, busca-se o devir que não se constitui em "atingir uma forma (identificação, imitação, Mimese), mas encontrar a zona de vizinhança, de indiscerni- 
bilidade ou de indiferenciação [...] não imprecisos nem gerais, mas imprevistos, não-preexistentes". (DELEUZE, 2011, p.11)

A outra, apresentada na paisagem II, é a noção de experiência de John Dewey. Nessa noção, em uma experiência artístico-estética, a relação controla ao mesmo tempo o agir e a percepção, sendo uma filosofia da experiência no âmago da educação e da arte, propondo que professores e artistas sejam conhecedores exímios do seu processo de aprender e que estejam com seus conjuntos de práticas em constante estado de reflexão. Para ter-se uma experiência, é preciso criar experiências, ser atravessado por ações, e, para que esta experiência se torne estética, dependerá do tempo disposto, de percepção e da reflexão desprendida para esse momento. Uma experiência estética consciente origina-se de um perceber, interpretar e compreender processos e procedimentos que adensam o agir/sentir/fazer, aproximando teoria e prática. E, portanto, com a experiência, seu material é vivenciado até o final, no qual sua conclusão "é uma consumação e não uma cessação" (DEWEY, 2010, p. 110).

Seguindo essas ideias filosóficas, a paisagem não está voltada para manifestações territoriais singulares, mas para o acontecimento ou a experiência que ocorre nela. Como cita Cauquelin: "E assim como o lugar (topos) é, segundo a definição aristotélica, o invólucro dos corpos que limita, a pretensa "paisagem" (lugarzinho: topion) nada é sem os corpos em ação que a ocupam" (2007, p. 49).

[Entre] paisagens surgem o acontecimento e a experiência, ambas reconfigurando outros modos de ser na formação docente e na formação do artista. O que está "entre" não corresponde necessariamente a um ou a outro modo de ser, mas aquilo que, de alguma forma, diz respeito aos dois. Nesse cruzamento, quais movimentos podem surgir? Que efeitos/paisagens sugerem? Que pode se passar entre dois domínios totalmente diferentes? Além dessas questões, como conciliar duas pesquisadoras no mesmo GP com teorizações tão diversas, mas que se complementam de modo paradoxal em uma relação disjunta?

\section{PAISAGEM I}

Nesta parte do texto, apresenta-se a pesquisa intitulada paisagens pedagógicas, que aposta na ética e na política da diferença como resistência a qualquer modelo representacional na esfera da formação docente em arte educação. Participam desse estudo investigativo estudantes de graduação e pós-graduação da Universidade do Estado de Santa Catarina (UDESC) desde o ano de 2016, propondo investigações sobre práticas pedagógicas e seus desdobramentos junto a formação docente em Artes Visuais, especialmente, nos seguintes aspectos: teoria pedagógica, metodologias de ensino, conteúdos, procedimentos de criação, tanto em arte quanto na docência. Essa proposição decorreu de uma pesquisa realizada em 2014 e 2015 denominada Arte e ensino [entre] margens, que evidenciou a necessidade daquela investigação para compreender com mais subsídios a relação pedagógica e poética imbricadas na formação docente. A questão metodológica da pesquisa é referenciada no método da cartografia com a finalidade de apresentar algumas paisagens pedagógicas presentes em práticas entrecruzadas pela formação docente e poética. A cartografia, 
referenciada nos princípios do rizoma de Gilles Deleuze e Félix Guattari (2004), atesta no pensamento sua força performática, sua pragmática: princípio "inteiramente voltado para uma experimentação ancorada no real". (Ibidem, 2004, p. 21) Na cartografia, nada se decalca e não há um único sentido para sua experimentação, nem uma mesma entrada. A realidade cartografada se apresenta como algo móvel, sem centro, em que a pesquisa é definida como caminho em um método que deve ser experimentado e não aplicado, ressignificando o rigor e a precisão na pesquisa, colocando-a mais próxima dos movimentos da vida.

Assim, a cartografia é compreendida como caminho que pressupõe uma orientação fluída, não prescritiva, sem objetivos previamente estabelecidos. Entretanto, não se trata de uma ação de pesquisa sem direção, pois o modo de pesquisar na cartografia não abre mão da orientação no percurso da pesquisa. Assim, a pesquisa não caminha no sentido de alcançar metas prefixadas, mas orienta-se para o desafio de um caminhar que traça no percurso suas próprias metas, sempre considerando os efeitos do processo do pesquisar sobre o objeto da pesquisa, o pesquisador e seus resultados (PASSOS; BARROS In PASSOS; KASTRUP; ESCÓSSIA, 2012, p. 17).

O que se observa nos planos cartográficos traçados até o momento é que os mesmos apontam para pistas em que a constituição docente é variável e o que passa entre as formações - artística e docente - acaba por influenciar toda a sua construção que, longe de ser identitária, permanece suspensa em uma série de variações. Essas não estão subordinadas a um "modelo de professor" que possa, talvez, ser repetível, mas se revela como algo ainda por vir, ou, como afirma Deleuze (2011, p.14), em algo que consiste em inventar um povo que falta. Portanto, a construção docente não possui uma única constituição identitária, pois por ela passam toda a sorte de devires - moleculares, femininos, infantis, imperceptíveis - que a fazem delirar, variar indefinidamente, borrando limites e fronteiras entre a docência e a arte.

Desse modo, o caminho da cartografia permite deslizar pelos vários modos de ser docente propondo lidar com o que vem se tornando cada vez mais discutido - a complexidade da experiência -, que por si é móvel, imprecisa e, portanto, imprevisível. A cartografia permite afirmar que o mundo não está lá para ser reconhecido, mas para ser construído numa experimentação incessante, para além de uma oposição entre objeto e acontecimento. Para os autores Tania Mara Galli Fonseca e Luis Artur Costa, percorrer essa oposição exige:

A criação de uma ontologia fluida, na qual nos vemos em meio a uma vertigem de devires em ação, [...] não sendo novidade para os profissionais que trabalham com a perspectiva da filosofia da diferença e da cartografia. Faz parte já da formação de um cartógrafo preparar seu olhar para desfazer "objetos" (coisas), deslizando de suas fronteiras aparentemente rígidas para uma concepção expressionista do mundo, tal como em um quadro de Van Gogh, Munch ou Pollock: as linhas se apresentam informes, selvagens em sua vibração intensa que explicita o ser como agenciamento de modos de ser que constitui estilísticas (por sua vez também agenciamentos de agenciamentos, em uma regressão infinita e paradoxal) (FONSECA; COSTA, In PASSOS; KASTRUP; TEDESCO, 2014, p. 260).

Paradoxal e infinita em agenciamentos, o movimento da cartografia na pesquisa 
paisagens pedagógicas insere-se em linhas-pensamentos, linhas-afectos, linhas-provocações. Apenas linhas. Em encontros, palavras e ideias movem a pesquisa, fluindo por entre a paralisia do pensamento pronto e da atividade-repetição, burocrática e administrativa, cada vez mais presente tanto na academia quanto nas escolas de modo geral. Para tanto, traçam-se linhas de fuga que movimentam ideias em torno de uma educação que promova encontros com pensamentos que aumentem a potência de existir, de criar linhas de voo, verdadeiras máquinas de guerra, que inauguram outros modos e fazeres de pesquisa em educação e arte.

Linha de fuga traçada pelo grupo dessa pesquisa que teima em encontrar alegria em discussões de teorias, imagens e metodologias para além de uma pesquisa-decalque, ao agenciar pessoas que se movem a pesquisar, compartilhando vidas, afectos, movimentos, ventos e devires. O que irrompe nessa intersecção é o acontecimento que sobe à superfície em um devir-ilimitado. Segundo Gilles Deleuze, "o devir-ilimitado torna-se o próprio acontecimento, ideal, incorporal, com todas as reviravoltas que the são próprias, do futuro e do passado, do ativo e do passivo, da causa e do efeito" (DELEUZE, 2003, p. 9).

Nessa acepção, o acontecimento é infinitamente divisível, sempre dois ao mesmo tempo, eternamente o que se passa e o que vai se passar. Assim, apresentam-se as práticas docentes, alternando o que se passou e o que se passa, confundindo-se, em alguns momentos, com a própria história do ensino de arte brasileiro. O que ocorre é que não são coisas ou estados de coisas, mas acontecimentos que subsistem e persistem na formação em licenciatura que, longe de formatar um modelo, permitem traçar as variações intrínsecas à formação docente.

De certo modo, o que ocorre é que se insere no pensamento desta pesquisa uma linha de liberdade livre da incumbência de representar algo, pois ela agencia um outro tipo de realidade que a história só consegue recalcar em um sistema pontual. À história como aquela que designa um ponto final contrapõe-se um ponto de exclamação! O finalmente na história designa o "ponto, como condenação à masmorra daquilo que não deve ser imprevisto: 0 acaso, as surpresas do acaso, 0 acontecimento" (LINS, 2012, p. 29). Então, para apreender o acaso e o acontecimento, nessa perspectiva, é preciso, como pesquisador, inscrever-se no campo das forças que reconstitui e/ou reinventa o plano de conhecimento e a realidade conhecida. Nessa inserção, a cartografia como caminho a ser trilhado possibilita orientar-se por uma diretriz não propriamente epistemológica, mas muito mais, ética, estética e política, uma vez que, em sua própria constituição como método, a cartografia apresenta-se como uma multiplicidade em torno do que difere, distanciando-se dos modelos metodológicos orientados pelos pressupostos da representação. Sua prática guarda sempre uma dimensão avessa a unificações, mergulhada que é na experiência singular. Por isso, é necessário ressaltar a necessidade da "posição firme do cartógrafo no que se refere à diretriz da investigação: o acesso/produção do plano de forças que responde pela criação/transformação de experiência" (PASSOS; KASTRUP; TEDESCO, 2014, p. 9). Cabe perguntar: o que move o pesquisador nesse campo de forças? Talvez, estar aberto ao intempestivo, "outro nome para dizer [...], a inocência do devir (isto é, o esquecimento contra a memória, a geografia contra a história, o mapa contra o decalque, o rizoma contra a arborescência)" (DELEUZE; GUATTARI in LINS, 2012, 
p. 27).

A partir desse campo de forças surge o pensamento que é forçado a pensar, aquele impulsivo, inventivo, indeterminado, aberto, impessoal, desnorteando o reino da representação, interpondo um pensamento sem imagem, sempre por vir, em um movimento incessante. Com isso, na pesquisa, o que cintila à superfície é o acontecimento, proliferando-se em direção a uma pluralidade infinita de modos de ser docente longe de um perfil identitário, como em um processo que compõe o que Pereira denomina de professoralidade. Segundo esse autor:

[...] a professoralidade não é uma identidade que um sujeito constrói ou assume ou incorpora, mas, de outro modo, é uma diferença que o sujeito produz em si. Vir a ser professor é vir a ser algo que não se vinha sendo, é diferir de si mesmo. E, no caso de ser uma diferença, não é a recorrência a um mesmo, a um modelo ou padrão. Por isso, a professoralidade não é, a meu ver, uma identidade: ela é uma diferença produzida no sujeito (PEREIRA, 2013, p. 35).

Desse modo, a construção da professoralidade não é algo estável a que se chegaria, mas a um estado de risco permanente, produzindo linhas de fuga em fluxos constantes. Nessa construção, que envolve fazer escolhas, o acontecimento, como campo de forças em intensidades variáveis, promove conexões com vários campos de saberes, entre eles, o pedagógico, o estético, o filosófico, o político e o ético, todos inseridos no contexto contemporâneo, sempre móvel e fluido. Portanto, também distante de uma representação única e estável.

\section{PAISAGEM II}

É nesta paisagem, em experiências pictóricas, que se situa o projeto de pesquisa intitulado $O$ estúdio de pintura como laboratório de ensino e aprendizagem nas Artes Visuais, no qual participam estudantes de graduação e pós-graduação da UDESC desde o ano de 2014, propondo investigações entre o campo da prática artística e da prática pedagógica. No âmbito de uma Universidade Pública, a pesquisa questiona como construir um espaço de ensino e aprendizagem que compreenda o tempo e o espaço no estúdio de pintura. Tal questão parte não somente da perspectiva de mapear metodologias operativas desenvolvidas na pesquisa em arte, mas do sentido de instaurar outro modo ou paisagem, gerando deslocamentos para uma consonância contemporânea frente à arte e à educação e que dinamize o processo formativo do artista professor neste espaço.

Não se diferencia o lugar do artista professor, e sim compreende-se o 'entre' como caminho formativo na pesquisa em artes visuais. Para o professor, a pesquisa em arte não se refere a pesquisas sobre arte (as quais poderão também se situarem em estruturas de reflexão e articulação), mas sim nas relações que o processo criativo instaura para o fazer/criar 'aula', que partem da articulação prática e teórica, e não o contrário. Compreende-se que a pesquisa sobre arte também tem eixo gerador no sentido de que o pesquisador ancora seu conhecimento em determinado momento/ estudo. No entanto, é o que ele produz (seja uma obra, ou uma aula, ou um projeto) que nos interessa como pesquisa em arte. A pesquisa em arte não exclui a reflexão 
sobre obras de outros artistas e referenciais teóricos; olha-os e pensa-os de modo diferenciado da pesquisa sobre arte. A referência imagética é constante, pois influencia a percepção diante da produção, agindo sobre singularidades, de acordo com a apreensão do olhar, tornando-se um emaranhado de referências que se transforma subjetivamente no processo. Para tanto, é preciso compreender que a feitura de uma obra ou de uma experimentação é repleta de acasos, imprevistos e insatisfações que, ao serem percebidos, tornam-se bússolas, demonstram caminhos, os quais são permeados por escolhas, por vezes um caminho incerto, para uma nova tentativa sem garantia de acertos. Não há um modelo. Diferentes situações são implicadas pela pesquisa em arte, situações da ordem do viver e da percepção sobre o que é vivido, as quais são conhecidas e questionadas especialmente por aqueles que vivenciam o percurso criador.

A pesquisa em arte pressupõe parâmetros metodológicos que se distinguem da pesquisa científica, mas que também se diferenciam da pesquisa da área social, como até mesmo se diferenciam da pesquisa sobre arte, concebida a partir do produto final. A pesquisa em arte constitui-se numa modalidade específica de pesquisa com características muito próximas de seu campo. Pressupõe uma abordagem específica do objeto artístico e requer questões metodológicas também específicas. Podemos extrapolar brincando e afirmar que não existe uma metodologia para pesquisa em artes visuais, mas sim esta modalidade de pesquisa é (s)cem modelo [...] (REY, 2002, p. 132).

A pesquisa em arte, por estabelecer relação íntima com a necessidade de processo, vai ao encontro da filosofia da poiética, pois "O objeto da Poiética se constitui pelo conjunto de efeitos de uma obra percebida, não é a obra acabada, nem a obra por fazer: é a obra se fazendo" (REY, 2002, p. 134, grifo nosso). O conceito envolve a "consciência das condutas criativas" (PASSERON, 2004, p. 9): saber como se cria, qual metodologia percorre o trabalho e o que imputa um sentido ao trabalho sendo feito são situações que incorporam a poiética. John Dewey (2010) tece reflexões sobre a experiência estética através de uma metáfora que se refere a caminhos e à transformação gerada ao percorrê-los. O filósofo relata que uma pedra, ao rolar morro abaixo, vivencia um percurso permeado por circunstâncias, entre repousos, e a retomada do movimento estabelece relações com as coisas e obstáculos que encontra. Tais relações funcionam como trocas proporcionadas pelo percurso, e assim com tudo o que veio antes e depois de seu repouso final. $O$ autor demonstra que, para se obter uma experiência, um fator relevante é o caminho. O modo como se desenvolvem interesses por suas situações e se criam relações é o que permite a experiência. Conforme Dewey:

Os inimigos do estético não são o prático nem o intelectual. São a monotonia, a desatenção para com as pendências, a submissão às convenções na prática e no procedimento intelectual. Abstinência rigorosa, submissão coagida e estreiteza, por um lado, desperdício, incoerência e complacência displicente, por outro, são desvios em direções opostas da unidade de uma experiência (2010, p. 117).

Os inimigos do estético apontados por Dewey também são os desvios do pró- 
prio fazer e do pensamento artístico. São os fatores que permitem o trabalho 'amornar', ser deixado de lado ou esquecido. Pode-se ponderar sobre a pesquisa em arte e o autoconhecimento que esta intenta por meio da filosofia da experiência de Dewey. Conhecer-se também é olhar para o Outro, para o mundo, para as situações e processos de criação que este olhar proporciona, que causam repouso ou que impulsionam.

Observando este contexto, Lampert (2016) salienta que todo objeto artístico poderá ter dimensões políticas, discursivas e pedagógicas, compreendendo a prática no estúdio de pintura como processo de um fazer criativo no qual se inclui a reflexão crítica e a produção plástica por meio da experimentação (e vice-versa), concebendo que a pintura poderá ser uma representação imaginária, mas que também denota incontestavelmente derivações sobre a estética. O desafio de teorizar a prática de ateliê requer a construção de uma robusta e defensiva estrutura para considerar a relação entre as teorias e as práticas, que intuem como a arte é feita (produzida), e como pode ser estudada e aprendida. A necessidade de ser cauteloso sobre descrever uma estrutura analítica para teorizar a prática artística como um lugar para a pesquisa é evidente. Qualquer estrutura sistemática tem o potencial de conduzir a uma nova ortodoxia como interesses preferidos e funções de métodos para normalizar práticas. A experiência no ateliê de pintura pode ser uma forma de investigação cognitiva, em que a pesquisa pode ser empreendida de forma suficientemente robusta e forte, para produzir conhecimento e compreensão, que é transformadora e confiável, e também social e culturalmente relevante. Assim como também poderá ser o lócus da consequência educacional de práticas que oferecem resultados e inclinam-se para mudar em relação a diferentes circunstâncias socioculturais. Trata-se de um lugar repleto de ideias e imagens que informam ações individuais, sociais e culturais.

A formação do professor de artes visuais perpassa por um sujeito artista professor (compreendemos que a pesquisa está implícita e inerente ao trabalho docente), pensando no processo de ensino e aprendizagem cotidiano, ultrapassando o limite entre o pessoal e o profissional. A prática reflexiva diária pode levar a procedimentos que partem desde a concepção de diários, mapas ou investigações que examinem problemas educativos por meio da criação artística, utilizando linguagens artísticas, e não apenas evidenciando estudos de caso ou pesquisas quantitativas.

Refletir (e produzir) sobre propostas de ensino/aprendizagem que relacionem teoria e prática é relevante para conectar a subjetividade da prática docente e o próprio processo de formação docente, usando o espaço do ateliê híbrido, como eixo e cartografia como meio de metodologia ou caminho a ser percorrido como possibilidade de trabalho. Conforme Passos, Kastrup; Escóssia (2012), a cartografia é um modo de construir uma realidade a partir daquela que já existe usando o coletivo, os processos subjetivos e a transversalidade da própria temática. Sendo assim, cria-se a possibilidade de estudar as relações entre a educação e o espaço/lugar/tempo do ateliê de arte. Os usos da cartografia e da narrativa, pensando a subjetividade, podem permitir agregar conceitos e perspectivas ao estudo sobre o ateliê e suas implicações pedagógicas.

A cartografia e o lugar do ateliê completam-se, compondo uma narrativa que condiz com a característica de um professor que também pensa na pesquisa e em uma produção artística, ambas vinculadas com sua prática docente, seja no espaço 
das oficinas, laboratórios, escolas, ensino formal ou não, até as galerias e museus, poderá ser vista como um caminho para um ensino de arte em consonância com a contemporaneidade.

\section{[ENTRE] PAISAGENS}

No item paisagem I aparece as variáveis e/ou variações de uma pesquisa flutuante, ainda em curso, que não busca a identidade, mas o acontecimento que se prolifera na formação de licenciatura entre a área de conhecimento Arte e a materialidade da arte como pesquisa artística. Nessa dimensão, o que atravessa os dois campos é a educação estética, que se configura em linhas diversas produzindo infinitas cartografias. Segundo Lins, "[...] a transversalidade é o eixo peculiar à construção da Estética como Acontecimento. Terreno fértil, propício ao exercício de um pensamento rizomático" (LINS, 2012, p. 22).

Essa transversalidade permite o exercício de um pensamento que se abre a leituras plurais da realidade da formação docente e artística, que supera a supremacia de uma única razão, sendo a transversalidade o próprio rizoma, ou seja, uma multiplicidade por onde passam intensidades em velocidades muito diferentes. Nesse exercício, as linhas escapam por todas as partes, permitindo ou não ao pesquisador segui-las para a composição de novas cartografias feitas a partir do escoamento dessas mesmas linhas.

[...] como em qualquer coisa, há linhas de articulação ou segmentaridade, estratos, territorialidades, mas também linhas de fuga, movimentos de desterritorialização e desestratificação. As velocidades comparadas de escoamento, conforme estas linhas, acarretam fenômenos de retardamento relativo, de viscosidade ou, ao contrário, de precipitação e de ruptura. (DELEUZE; GUATTARI, 2004, p. 11).

Nessa composição, a estética aparece como acontecimento entre as coisas, sempre no meio, como em um movimento transversal que carrega a potencialidade da vida em um plano não transcendente, mas puramente imanente. Para Lins, a estética como acontecimento é uma filosofia que compartilha com a arte outra exigência que não é aquela da representação, mas como estética dos sentidos, ou como ele diz, um verdadeiro arquipélago de sentidos, que surgem da intersecção de um problema com um pensamento. Cabe salientar que o sentido não preexiste ao acontecimento que o produz, pois "o real em si" é o caos, uma espécie de efetividade sem efetuação (LINS, 2012, p. 25). Portanto, uma filosofia que não se protege do caos, mas o mergulha, fazendo emergir os possíveis desse real, eliminando toda sua relação com uma representação de mundo. O caos, nesse caso, é concebido como caos-gênese (GUATTARI, 2012), comprometido com uma abertura a experiências singulares, que afrontam o que está estabilizado e/ou normatizado na educação em arte. Normas que, em geral, transformam-se em hábitos que impedem qualquer potencialidade de criação, de espanto, ou de novas possibilidades em modos de ser docente.

Desse modo, atravessar o caos da pesquisa sem a explicar ou comentar em uma travessia que ordena apenas planos e paisagens singulares que configuram o aconte- 
cimento, continua sendo, para o grupo, algo a ser feito com arte. Pois, como afirma Deleuze, o acontecimento nunca é o que acontece ou um simples estado de coisas, uma vez que se situa no interstício entre o sensível e o pensamento, entre arte e docência, lugar de uma gênese do sentido sempre renovada. Uma gênese ambulante, órfã, nômade, como um jeito criativo de revisitar e fazer respirar os conceitos, como diria Deleuze.

Eis por que pensamos a Estética como Acontecimento, feita arte que exige da existência algo muito mais forte do que ela nos proporciona. Potente, inventora, a vida, às vezes, pede socorro! A vida parece estar com medo [...] (LINS, 2012, p. 30).

A vida parece estar com medo, como diz Lins, algo que parece exigir novos modos que a levem à invenção de outros possíveis. Talvez, levá-la a uma filosofia da arte habitada por disparidades e devires artísticos em que a estética como acontecimento se apresente como intercessora primordial da vida em todos os níveis. Em outros termos, seria pensar a cartografia das linhas-pensamentos-moventes da pesquisa como forças que escapam da dominante biológica e finita da vida, pois a mesma demanda ser inventada, assim como a educação e a arte.

Por outro lado, no item Paisagem II, a prerrogativa relevante para pensarmos na atualização do conceito de experiência cunhado por Dewey é a de recusar as verdades absolutas e as dicotomias, sobretudo no caminho da pesquisa em arte e arte educação. Dewey defende um princípio de continuidade em sua filosofia, na qual essa continuidade confere uma unidade, que nada se aproxima de imutabilidade. Para Dewey, unidade implica flexibilidade e continuidade de interações, ou mesmo a busca por acontecimentos. É o cerne da relação entre o homem e o mundo. A experiência é uma espiral. Seu fluxo contínuo unifica a percepção entre o que é feito e o que é suportável; cria conexões com experiências anteriores - uma observação constante entre o que existiu, existe e existirá. $O$ processo é vivenciado conscientemente. A ansiedade e as frustrações, que fazem parte da vida cotidiana e estão presentes no processo criativo, não são impeditivas para que a inteligência organize a consumação da experiência pulsante; discernimento entre ações e desejos. Não há dicotomias, fragmentações entre inteligência e sensibilidade. É o próprio processo do viver unificado ao ambiente tomando consciência de si - esse conjunto consciente propicia ao sujeito uma experiência. O estético, na filosofia da arte de John Dewey, não é um fator externo e que se "lança" para a experiência. Tampouco está relacionado ao luxo ou é idealizado por qualquer corrente de pensamento transcendental.

Portanto, o grupo [Entre] Paisagens deriva sobre caminhos que evidenciam a prática pedagógica e a prática artística, que colaboram com o que Anne Cauquelin (2007) reporta em 'A invenção da paisagem', que a paisagem não é apenas parte da natureza, mas sim uma construção conceitual humana, que busca seu equivalente na natureza. A paisagem mostra-se como um conceito aberto, evidenciando um modelo mais cultural do que ideal estético. Dessa forma, não tratam somente do espaço e tempo, mas norteiam encontros que são apreendidos da realidade do mundo por meio das experiências daqueles que nos cercam e legitimam para nós 
sua presença. Assim, a paisagem torna-se metáfora ampliada para a construção do conhecimento produzido pelo pensamento visual por meio da arte e da educação.

\section{Referências}

CAUQUELIN, Anne. A invenção da paisagem. Tradução: Marcos Marcionilo. São Paulo: Martins, 2007. (Coleção Todas as Artes).

DELEUZE, Gilles. Lógica do sentido. 4. ed. Tradução: Luiz Roberto Salinas Fortes. São Paulo: Editora Perspectiva S.A., 2003.

Crítica e clínica. $2^{\mathfrak{a}}$ ed.Tradução de Peter Pál Pelbart. São Paulo: Ed.

34,2011

; GUATTARI, Félix. Mil platôs. capitalismo e esquizofrenia - vol. 1. Tradução:

Aurélio Guerra Neto; Célia Pinto Costa. Rio de Janeiro: Editora 34, 2004.

DEWEY, John. Arte como experiência. São Paulo: Martins Fontes, 2010.

FONSECA, Tania Mara Galli; COSTA, Luis Artur. As durações do devir. como construir objetos-problema com a cartografia. In: PASSOS, Eduardo; KASTRUP, Virgínia; TEDESCO, Silvia (orgs.). Pistas do método da cartografia: a experiência da pesquisa e o plano comum. Porto Alegre: Sulina, 2014.

GUATTARI, Félix. Caosmose: um novo paradigma estético. São Paulo: Editora 34, 2012.

LAMPERT, Jociele; GOULART, Tharciana; FACCO, Marta. A pesquisa em arte na arte educação: reflexões sobre "inventações" no ateliê de pintura. In: Anais do 26 Encontro Nacional dos Pesquisadores em Artes Plásticas. Campinas, São Paulo, 2017.

LINS, Daniel. Estética como acontecimento: o corpo sem órgãos. São Paulo: Lumme Editor, 2012.

MADERUELO, Javier. Paisaje: un término artístico. In: BULHÕES, Maria Amélia; KERN, Maria Lúcia B. Paisagem: desdobramentos e perspectivas contemporâneas. Editora UFRGS, 2010.

PASSERON, René. A poiética em questão. Revista Porto Arte, Porto Alegre, n. 21, vol. 1, jul./nov. 2004. Disponível em: <http://seer.ufrgs.br/index.php/PortoArte/article/ view/27885/16492>. Acesso em: 17 maio 2016.

PASSOS, Eduardo; BARROS, Regina benevides de. A cartografia como método de pesquisa-intervenção. In: PASSOS, Eduardo; KASTRUP, Virgínia; ESCÓSSIA, Liliana da (orgs.). Pistas do método da cartografia: pesquisa-intervenção e produção de subjetividade. Porto Alegre: Sulina, 2012. 
PEREIRA, Marcos Villela. Estética da professoralidade: um estudo crítico sobre a formação do professor. Santa Maria: Editora da UFSM, 2013.

REY, Sandra. Por uma abordagem metodológica da pesquisa em artes visuais. In: BRITES, Blanca; TESLER, Elida (orgs.). O meio como ponto zero: metodologia de pesquisa em Artes Plásticas. Porto Alegre: UFRGS, 2002. pp.123-140.

WOSNIAK, F.; LAMPERT, Jociele. Sobre o ensino/aprendizagem em Artes Visuais ou arte como experiência. In: Seminário comemorativo do centenário do livro Democracia e Educação, 2016, São Paulo. Seminário comemorativo do centenário do livro Democracia e Educação: a Filosofia da Educação de John Dewey em debate. Paraná: Londrina, 2016, vol. 1, pp. 39-54. Disponível em: <http://www.uel.br/eventos/centenariode/>. ISBN978-85-7846-365-6. Acesso em: 08 maio 2016. 